\title{
Adjuvant endocrine therapy after breast cancer: a qualitative study of factors associated with adherence
}

This article was published in the following Dove Press journal:

Patient Preference and Adherence

\author{
Jo Brett ${ }^{1}$ \\ Mary Boulton' \\ Debbie Fenlon² \\ Nick J Hulbert-Williams ${ }^{3}$ \\ Fiona MWalter ${ }^{4}$ \\ Peter Donnelly ${ }^{5}$ \\ Bernadette A Lavery ${ }^{6}$ \\ Adrienne Morgan ${ }^{7}$ \\ Carolyn Morris ${ }^{7}$ \\ Eila K Watson' \\ 'Faculty of Health and Life Sciences, \\ Oxford Brookes University, Oxford, \\ ${ }^{2}$ College of Human and Health \\ Sciences, Swansea University, Swansea, \\ Wales, ${ }^{3}$ Department of Psychology, \\ Chester Research Unit for the \\ Psychology of Health, University \\ of Chester, Chester, ${ }^{4}$ Department \\ of Public Health and Primary Care, \\ University of Cambridge, Cambridge, \\ ${ }^{5}$ South Devon Healthcare NHS \\ Foundation Trust, Torbay Hospital, \\ Torquay, ${ }^{6}$ Cancer Services, Oxford \\ University Hospitals Foundation NHS \\ Trust, Oxford, ${ }^{7}$ Independent Cancer \\ Patients' Voice, London, UK
}

Correspondence: Jo Brett Faculty of Health and Life Sciences, Oxford Brookes University, Jack Straws Lane, Marston, Oxford OX3 OFL, UK Tel +44 I865 482696 Email jbrett@brookes.ac.uk
Introduction: Despite evidence of the efficacy of adjuvant endocrine therapy (AET) in reducing the risk of recurrence and mortality after treatment for primary breast cancer, adherence to AET is suboptimal. This study aimed to explore factors that influence adherence and nonadherence to AET following breast cancer to inform the development of supportive interventions.

Methods: Interviews were conducted with 32 women who had been prescribed AET, 2-4 years following their diagnosis of breast cancer. Both adherers $(n=19)$ and nonadherers $(n=13)$ were recruited. The analysis was conducted using the Framework approach.

Results: Factors associated with adherence were as follows: managing side effects including information and advice on side effects and taking control of side effects, supportive relationships, and personal influences. Factors associated with nonadherence were as follows: burden of side effects, feeling unsupported, concerns about long-term AET use, regaining normality, including valuing the quality of life over length of life, and risk perception.

Conclusion: Provision of timely information to prepare women for the potential side effects of AET and education on medication management strategies are needed, including provision of timely and accurate information on the efficacy of AET in reducing breast cancer recurrence and on potential side effects and ways to manage these should they arise. Trust in the doctorpatient relationship and clear patient pathways for bothersome side effects and concerns with AET are important. Training and education on AET for GPs should be considered alongside novel care pathways such as primary care nurse cancer care review and community pharmacist follow-up.

Keywords: hormone therapy, oncology, patient experiences, support, follow-up

\section{Introduction}

Breast cancer is the most common cancer among women worldwide. ${ }^{1}$ Approximately 55,000 women in the UK are diagnosed every year, and one in five of them experience a recurrence at some point following primary treatment. ${ }^{2,3}$ Adjuvant endocrine therapies (AETs) such as tamoxifen and aromatase inhibitors (AIs) have proven clinical benefit, reducing the risk of recurrence for women with estrogen receptorpositive breast cancer by $11.8 \%$ and mortality by $9.2 \%$ over 5 years. ${ }^{4}$ Guidelines until recently recommended 5 years of treatment, but following trial evidence, this is being extended to 10 years. ${ }^{5-9}$

Despite the known efficacy of AET, ${ }^{5-9}$ adherence to AET is suboptimal. In a systematic review of 29 studies, adherence to AET over 5 years ranged from 41 to $72 \% .{ }^{10}$ Previous studies have reported that $<50 \%$ of women complete a full 5 years 
of AET, leading to increased recurrence and a $20 \%$ rise in breast cancer mortality, as well as higher medical costs and poorer quality of life. ${ }^{11-13}$ As the time to discharge from routine follow-up decreases and the recommended time to take AET increases to 10 years, adherence rates could be expected to fall further.

While previous quantitative studies have identified factors associated with nonadherence to AET, including side effects, lack of knowledge about AET, and medication beliefs, ${ }^{14-16}$ only limited qualitative research has been conducted in this area. ${ }^{17,18}$ In order to develop patient-centered interventions and guide clinical practice to improve medication adherence, a thorough understanding of women's perspectives on this topic is essential. ${ }^{19}$

Using interviews with women, this study aimed to explore, in depth, the factors that influence whether women adhere to or do not adhere to AET to inform the development of interventions to improve adherence and ultimately to improve outcomes for women who have been treated for breast cancer.

\section{Methods}

A sample of women who had been prescribed AET following treatment for breast cancer were recruited 2-4 years after initiating the treatment. The sample included both adherers and nonadherers:

- Adherers were defined as still taking the medication as recommended.

- Nonadherers were defined as having initiated AET but now had stopped taking the medication.

Participants were identified and recruited through two sources. Initially, women who had taken part in a previous questionnaire survey $(n=292)$ and reported adherence or nonadherence to AET were asked whether they would participate in an interview. ${ }^{14}$ As the number of nonadherers recruited from this source was small $(n=5)$, a second group of women who self-reported nonadherence to AET was recruited through 1 month advertisements on the following two UK charity website forums: Independent Cancer Patients' Voice and Breast Cancer Care $(n=8)$.

Semistructured interviews were conducted by JB either at the woman's home or at another place of her choice. Interviews lasted between 41 and 103 minutes (mean 60 minutes). All interviews were digitally recorded and transcribed verbatim.

Analysis was carried out using the Framework approach with adherers and nonadherers analysed as two separate groups. ${ }^{20} \mathrm{JB}$ read all the transcripts, and both $\mathrm{MB}$ and $\mathrm{EW}$ read a selection of the same transcripts in order to gain an overview of the women's accounts and identify recurring themes. This led to the development of a coding framework. Two transcripts from each group were coded by at least two of the authors. Coded transcripts were compared and codes further refined and then grouped together into broader categories. The Framework approach allows both inductive and deductive analyses. ${ }^{20}$ Codes and categories were therefore derived both inductively from the women's accounts and deductively from relevant literature, for example, the necessity-concerns framework developed by Horne et al. ${ }^{21,22}$

The coding framework was then applied to index the transcripts, that is, a code was attached to each relevant passage of text using the software NVivo 10. JB coded all interviews, and $\mathrm{MB}$ coded one from each group to assess consistency. When indexing was complete, a matrix was created, with a page for each category and one code per column and one participant per row. For each participant, data were abstracted for each code and summarized in the appropriate cell on the matrix, with notes of supporting quotes. The matrix was then reviewed in relation to the research questions and themes generated by making comparisons and looking for connections across cells, both within and between participants. Interpretation of the data is reported here using relevant quotes to illustrate.

\section{Ethics}

Ethics approval was obtained for this study from the UK National Health Service National Research Ethics Service (NHS NRES: 09/H050501/44) and from the Oxford Brookes University Research Ethics Committee (UREC: 140832). In accordance with ethics regulations, consent was obtained from all patients to participate in the study.

\section{Results}

Interviews were conducted with 32 women, all of whom had been prescribed AET after treatment for primary breast cancer. Participants include 19 adherers and 13 nonadherers from England and Wales. Characteristics of the sample are listed in Table 1.

For those who continued to take their medication, three key themes which facilitated adherence were identified. For those who had discontinued their medication, five key themes associated with nonadherence were identified.

\section{Factors associated with adherence to AET Managing side effects}

\section{Information and advice}

Receiving timely information and expert advice were important to participants. Adherers valued timely and relevant 
Table I Characteristics of sample

\begin{tabular}{|c|c|c|}
\hline & $\begin{array}{l}\text { Adherers } \\
(n=19)\end{array}$ & $\begin{array}{l}\text { Non-adherers } \\
(n=13)\end{array}$ \\
\hline \multicolumn{3}{|l|}{ Recruitment method } \\
\hline Questionnaire survey & 19 & 5 \\
\hline UK charity forums & 0 & 8 \\
\hline \multicolumn{3}{|l|}{ Age (years) } \\
\hline Range & $37-77$ & $53-76$ \\
\hline Median & 59 & 64 \\
\hline \multicolumn{3}{|l|}{ Marital status, n (\%) } \\
\hline Married & $15(79)$ & $10(77)$ \\
\hline Single & $\mathrm{I}(5)$ & $2(15)$ \\
\hline Separated & - & $\mathrm{I}(8)$ \\
\hline Widow & $3(16)$ & - \\
\hline \multicolumn{3}{|l|}{ Education, n (\%) } \\
\hline “،'O’ O” level, GCSE, or equivalent & I (5) & - \\
\hline “" A' A" level or equivalent & - & - \\
\hline College or university degree, & $16(84)$ & $9(69)$ \\
\hline HND or HNC & - & - \\
\hline Postgraduate qualification & $2(11)$ & $4(3 I)$ \\
\hline \multicolumn{3}{|l|}{ Type of AET, $n(\%)$} \\
\hline Tamoxifen & $13(68)$ & $6(46)$ \\
\hline Aromatase inhibitor & $3(16)$ & I (6) \\
\hline Swapped & $3(16)$ & $6(46)$ \\
\hline
\end{tabular}

Abbreviation: AET, adjuvant endocrine therapy.

information that they sought from a range of sources including health professionals, the Internet, and other women taking AET. Many would have liked more information in relation to side effects than they received:

I would have liked more information to prepare for the side effects. I was given lots of information about the side effects of chemotherapy and how to manage them, but I wasn't expecting the side effects of AET. So perhaps that made it worse. [P1 adherer]

For some adherers, the source of information was also important and advice provided by a trusted doctor was particularly valued in guiding their behavior:

I wanted to know more about why I was taking it and he went into a lot of detail of how it works. [If my doctor says] it reduces the risk of the cancer coming back, I'd be mad not to take it. [P19 adherer]

I must admit I take it - if they [doctors] say it's a good idea I'm very much [...] I think because my experience has been so positive with them [doctors] I've not come away doubting anything. [P2 adherer]

For others, lack of timely information had meant delay in attributing the side effects to AET lead to anxiety and concern about other conditions:

I thought it was the long-term effects of chemotherapy, so I thought it would improve. When it didn't long-term,
I began to realise it was possibly the hormone therapy.

[P17 adherer]

\section{Taking control}

Adherers seemed motivated to manage the side effects caused by AET and to take control over their bodies again. Some had sought information from the Internet or online forums on ways to adapt their lifestyle to help them tolerate their medication, such as changing their diet, increasing the exercise they took, and decreasing their alcohol and caffeine intake, and also on coping strategies that helped alleviate side effects such as using "chill" pillows, drinking ice water, and wearing thin layers of clothes.

I read on the internet about looking after myself $[\ldots]$ I eat much healthier now, and avoid alcohol and caffeine.

A bit boring, but it helps. The side effects are less now. [P7 adherer]

The online forum had other women chatting about it [...] the 'chill' pillows are great at night - I bought it online. [P1 adherer]

I wanted to be able to do something for myself. I wanted to be able to adapt and have some way of coping with the side effects. I started by eating more healthily. It was a way of taking back control. [P5 adherer]

\section{Supportive relationships}

Adherers found supportive relationships from family and health professionals valuable in motivating them in continued use of AETs. Some spoke about supportive husbands, family, or friends and how their support enabled them to carry on:

He [husband] is brilliant. He's very understanding - he has been with me $100 \%$ through everything. He has gone to hospital appointments with me but he just worries about how I feel. [P6 adherer]

Others described a positive and supportive relationship with their surgeon, oncologist, or GP, whose care and concern encouraged continuation with the medication:

I had a long conversation with him [GP] about it - he really cared. He swapped me on to this one - I know he is doing what he can. If you feel someone cares, it kind of encourages you to keep going, if you know what I mean. [P18 adherer]

\section{Personal influences}

Several adherers spoke about their responsibility toward others as important in their decision to continue taking AET. Adherers who had young children at home spoke about their 
adherence to AET in terms of their commitment to their children and their need to stay alive and healthy for their sake, whatever the cost to themselves.

I will carry on despite how I feel just because it's the only thing I can do and I'll do anything I can because of the kids really - I do want to be around [for them]. [P1, adherer]

Similarly, another woman continued taking her medication for the sake of her husband whose first wife had died of breast cancer, despite the weight gain she experienced and its impact on her confidence to continue working as a health advisor:

I really didn't want to take it [because of weight gain] and I have to say the only reason I have taken it, I think, it's because of my husband. Because e lost his first wife to breast cancer and I think I would be really selfish if I didn't take it for him but if it had been me I might not have taken it. [P6 adherer]

For some women, it was their previous experience of loss to cancer that influenced their decision. Some adherers had experienced the loss of loved ones from cancer, and this experience provided the motivation to continue with their medication. They perceived AET as a potentially life-saving "safety net" and were more likely to want to continue for 10 years. In the following examples, one woman had lost her mother after breast cancer recurred when she stopped taking tamoxifen, while the other woman had lost both her husband and colleague to cancer:

[...] [my mother's] trouble started up again when she stopped the tamoxifen so I have got that double idea that I'm safe while I'm on it. [P12 adherer]

My husband died of cancer in 2002 [...] Then in 2006 [...] my colleague died and I was diagnosed in 2010. So that was just four years, so you do think 'Oh my god, that's your death sentence' $[. .$.$] you just want to take it for$ as long as possible [P8 adherer]

\section{Factors associated with nonadherence to AET}

\section{The burden of side effects}

There was considerable heterogeneity in side effects described by nonadherers, and nonadherers tended to perceive themselves as suffering more from the severity and impact of side effects on their daily life than adherers. These included hot flushes, weight gain, vaginal discharge or dryness, joint aches and tiredness, lack of energy, mood swings, and depression. Women described how these side effects had disrupted their day-to-day lives and interactions with others in ways they found difficult to manage. Several women spoke about deep depression and mood swings, which they originally attributed to the stress of diagnosis and active treatment but over time associated with AET.

I turned into a monster over the few months following chemotherapy. I thought it was the stress of what I had been through, but it went on and on. I read on the internet that it could be the tamoxifen. I felt depressed and would swing into a temper for no reason. [P22 nonadherer]

It [tamoxifen] altered my mind [...] I felt almost suicidal with it. I didn't realise it was the drug until I got sick and didn't take it for a week. I felt so much better. [P21 nonadherer]

Some side effects were described as frequent, severe, and unpredictable, thereby restricting social activities and affecting friendships and relationships. This also gave rise to a loss of confidence and loss of motivation in life, leading to social isolation.

And I didn't want to go out and I became quite withdrawn really, so no, it wasn't acceptable. [P20 nonadherer]

I didn't really feel like doing anything. I carried on going to work, that was fine. I just couldn't be bothered to do anything out of work - like meet friends, see family. I just wanted to vegetate at home. [P24 nonadherer]

In some cases, side effects impacted on the women's confidence to work. One nonadherer described how her weight gain and body image had an impact on her role as a fitness instructor:

I knew quite a few and people who knew women who had put on a lot of weight which they blamed on the tamoxifen [...] How am I going to teach [aerobics] when I look like a balloon? [...] So that was a problem and that was all part of the hysteria. [P27 nonadherer]

While women tried to hide their side effects and maintain normality, they were also aware that the side effects impacted on their partners and friends.

I got thrown into the menopause. [...] [O]ne of the things that upset me most at the time [was that] I lost all interest in sex overnight - it didn't help my husband as you can imagine. [P30 nonadherer]

I talk to my friends but not for very long and not in any detail partly because I don't want [them] to think 'I'm not going to bother seeing [name of participant] you know.' - They are only going to go - 'oh she's depressed or something'. [P31 nonadherer]

Women were often unprepared for side effects. Initial information on AET was provided alongside other treatment 
plans just after diagnosis, but nonadherers struggled to absorb information on side effects at this time, as their attention was focused on active treatment. As a consequence, they were unprepared for the side effects of AETs and the impact on their lives.

I am sure I'd been told but you are suddenly bombarded with so much information. Not that people mean to do that but there is a lot to contend with at a time when you are not really taking it in. [P21 nonadherer]

If someone had said to me, these are the side effects that other women report - say $20 \%$ of women have this side effect, and if you get it come back and we can help you with it, then that would have been great. It's a lack of information that's the problem. [P26 nonadherer]

\section{Feeling unsupported}

Some nonadherers described "falling through the gaps" in the health care system once they had been discharged from hospital and were uncertain where to turn for support:

You have the hospital that dealt with the issue and then after you have come out of hospital it's the GP but the GP just refers you back to the hospital. So you have that triangle [...] they forget to look at you as a whole person [...] They are only interested in their own department. [P25 nonadherer]

Many nonadherers appeared unaware that their follow-up care had been transferred from the hospital to the GP. There was limited contact with their GPs as, despite ongoing prescriptions coming from their primary care practice, most of the women ordered their prescriptions online or over the phone and collected them from their local pharmacy. In addition, they were not confident that their GP had appropriate expertise regarding their AET and preferred to contact the hospital if they had any issues to discuss.

Don't get me wrong. My GP is lovely. But they don't know much about treatments for breast cancer. I'd rather talk to someone at the hospital. [P22 nonadherer]

Similarly, while most described their relationship with the breast care nurses (BCNs) as supportive and caring, they felt that the BCNs had limited time and had to prioritize support for women in having surgery, or on chemotherapy or radiation treatment. They therefore hesitated to ask them for advice around AET.

The breast care nurses were lovely, but rushed off their feet. You didn't want to disturb them unless it was life or death, if you know what I mean. They had a lot of people to see who had far greater problems than me. [P23 nonadherer]
Women felt that health professionals were being conservative about what they told them. One woman spoke of how the lack of interest and support in how she was dealing with side effects had led her to discontinue using the drug.

They are cautious with the amount of information they give you. You can tell they are not telling you everything. I can understand why they do this, but I would have preferred more information. [P31 nonadherer]

They answer questions but very much within their own confines. [P27 nonadherer]

I just took myself off it so obviously I felt that nobody was interested - I think there needs to be follow-up for hormone therapy. [P31 nonadherer]

\section{Concerns about long-term AET use}

Nonadherers were often skeptical of the benefits of AET and concerned about its toxicity. The following woman, for example, felt that there was little to be gained from taking the medication long term, once she had been free of cancer for 2 years:

I'd taken it for 2 years. I'd given it a go. It's been two years since the breast cancer - I feel back to normal now, I don't think it will make much difference now. [P20 nonadherer]

Another had stopped taking AETs because of her concern for the way that they had affected her physically.

It scared me what it did to me [...] I felt that I was drying up from the inside [...] I think my vision went slightly blurry and I felt older with aches and pains [...] dry skin and even felt that my teeth were slightly loose. [P29 nonadherer]

For some nonadherers, their general concerns about taking any medication long term underpinned their decision to discontinue medication.

I just don't like taking medication - I never take headache tablets I think in the long run they are all harmful. [P27 nonadherer]

\section{Regaining normality}

Most of the nonadherers had stopped taking their medication 1-2 years after taking it as prescribed. For some, their initial nonadherence was not based on a conscious decision but happened unintentionally. However, once the precedent had been set and the consequences had been perceived as a welcome relief from the grind of taking them or the burden of side effects, periods of temporary suspension and then a permanent discontinuation tended to follow. 
I stopped taking them for a couple of weeks while I was on holiday. I'd not taken them before, when I had flu for a week, and realised I felt better not taking them. So I wanted to enjoy my holiday. Get away from the grind of taking them. I just never went back to them. I meant to, it was just the longer I didn't take them [...] [P23 nonadherer]

Some women described "wanting to feel better" and not wanting to feel "ill" anymore and welcomed the release that stopping their medication brought. There was a sense that the side effects of the drugs prevented them from getting back to normal life.

It just stops you getting on with your life. You have been through surgery, then chemotherapy, then you take the hormone drugs. You get to the stage when you want to get back to normal, but these drugs stop you doing that. [P25 nonadherer]

Valuing the quality of life over length of life emerged as important for some women. For these women, the importance of a good quality of life for their remaining years, with no side effects of AET, outweighed the risk of recurrence and provided a justification for stopping their medication.

I keep thinking OK - you're 73 and it's interesting when you are old what it is [...] You want to enjoy the life you have left. You don't want to be on medication that makes you suffer and then die. [P21 nonadherer]

I think you need to take life by the horns. You make that decision and take the consequences. I took the decision not to continue because I wanted my normal life again. It is about weighing up what is important to you, not the doctor. [P26 nonadherer]

\section{Risk perception and understanding the risk}

Women perceived their risks of recurrence differently. Several of the nonadherers believed that they were at low risk of the cancer recurring. Statistics was complex, and some women found them difficult to understand; there was a misconception around whether they really needed to continue with AET.

It's a difficult one, but I feel it isn't making that much difference to me because I'm low risk anyway. [P28 nonadherer]

I was Stage 2, so I wasn't super high risk and I wasn't super low risk - moderate. If I had been higher risk would it have changed [...] a high risk of it coming back could have been different. [P23 nonadherer]
One woman felt that the doctor changed the statistics in an effort to persuade her to adhere to AET, causing confusion and distrust with the doctor:

I think he said look you are $20 \%$ better off on this - you are $20 \%$ less likely for it to comeback and I questioned it a bit - and I said I don't want to take it - but he said but you're $40 \%$ better off when you take it - but I thought of saying but you didn't say that last time - to be fair well you know these are statistics - statistics can trick you - you can prove anything with statistics - and then when I really thought I really don't want to do this and he went Oh and the statistics went the other way - and he said you're only $10 \%$ better off anyway. [P27 nonadherer]

\section{Discussion}

This qualitative study explored factors influencing adherence to AET in women with early-stage breast cancer. Factors that influenced continued adherence included provision of timely expert information about AET, self-efficacy to manage side effects, and supportive relationships with health professionals and family members. Doing everything possible to reduce the risk of recurrence for the sake of family members and fear generated from past experience of cancer were also strong drivers promoting adherence. Women who had discontinued AET described more burdensome side effects, held more negative beliefs about the effectiveness of AET, perceived continuing AET as a barrier to regaining normality in their lives, and placed a greater value on the quality of life over quantity of life. In comparison to women who continued with treatment, they also seemed to feel less supported by health care professionals.

Understanding why people adhere or do not adhere to prescribed medication is a complex issue. A recent metaanalysis of medication adherence in 22 different chronic diseases reports that across the range of included studies, higher adherence was associated with stronger perceptions of necessity of treatment and fewer concerns about treatment. ${ }^{21}$ The necessity-concerns framework hypothesizes that if concerns about medication outweigh the perceived necessity of taking the medication, then nonadherence is likely, and if the perceived necessity to take the medication outweighs the concerns, adherence is likely. ${ }^{22}$ This framework has previously been used to assess the beliefs and perceptions of treatment for breast cancer ${ }^{23-25}$ and other cancers. ${ }^{26,27}$ Women in our study often appeared to weigh up their beliefs about AET and their fears of recurrence alongside their experiences of the treatment and its impact on their daily lives to inform 
whether they adhere or not, and thus our findings fit well with this theoretical framework.

Our findings are consistent with and add depth to previous quantitative studies, including our own, which have addressed this topic. ${ }^{14,15}$ There have been only two previous qualitative studies conducted in this area. ${ }^{17,18}$ Harrow et al's ${ }^{17}$ study focused mainly on the experiences of women who were adherers to AET. The burden of side effects was reported, and the study concluded that the advice, support, and monitoring needed for adherence are not routinely offered in conventional follow-up settings. Cahir et al ${ }^{18}$ interviewed both adherers and nonadherers in Ireland. This study identified modifiable influences on hormonal therapy medication taking behavior including barriers and enablers to AET across the following three strata: beliefs about consequences, medication use, intentions and goals, and behavior regulation. Our findings are consistent with, and add weight to, the findings from these two studies.

Nonadherers in our study reported that a desire to feel "normal" again led to discontinuation with AET. A previous study found that while $90 \%$ of women adhered to AET in the first year, this figure dropped to $50 \%$ by the fifth year. ${ }^{11}$ Nonadherence may therefore coincide with a false sense of security of being "better" or a sense of returning to normality over time that may tip the balance of the necessityconcerns framework described by Horne et al, ${ }^{22}$ leading to nonadherence. It may also coincide with declining belief in the efficacy of hormonal therapy; this is consistent with findings from previous quantitative studies, which found that negative beliefs in the effectiveness of AET can influence nonadherence. ${ }^{14,15}$ Studies report that in chronic diseases, prioritization of the importance of medication intake declines over time combined with issues of medication being seen as a reminder of the patients' condition at a time when they are feeling well again and ongoing medication makes the person feel old or bad about themselves. ${ }^{28}$ As this study reports, permanent discontinuation often follows an unintentional period of temporary suspension, such as illness and forgetting to take tablets away with them. The feeling of normality during the temporary suspension can lead to intentional discontinuation.

Our findings have a number of implications for practice (refer Box 10). First, it is important that women receive timely information and discussion about AET in order to understand the benefits of taking AET as prescribed to ensure that they are adequately prepared for side effects that may occur and that they are equipped with coping strategies and information on where to seek support either through professional channels or other forms of support. The importance of well-timed information within the cancer trajectory has been widely recognized as important. ${ }^{29-31} \mathrm{~A}$ lack of adequate preparation for the impact of side effects has been shown to have a negative psychological response to cancer treatments. Where patients receive good preparation and education from health professionals, this empowers and enables them to cope better. ${ }^{32}$

Providing clear explanations of benefits and risks associated with taking and not taking AET is also important. ${ }^{33}$ This is often not clearly communicated by health professionals. The challenge is to continue trying to improve risk communication in health care, turning data into something more meaningful, relevant, and useful for individual patients. This could be achieved by adopting simple and practical strategies such as decision aids, tailored information, and consultation summaries informed by the best available evidence base. ${ }^{34}$

It is important for women to be able to discuss the potential difficulties of remaining adherent with long-term therapy and for health professionals to provide information and instill confidence in long-term management of hormone therapy. ${ }^{35}$ Health professionals should follow a patient-centered approach to care that promotes active patient involvement in management and coping strategies around AET, which in turn empowers women to take the control of their medication regime. ${ }^{36}$ Problem-solving techniques or cognitive behavioral techniques have potential to overcome the barriers to adherence and may improve communication channels with health professionals. ${ }^{37}$ Increased communication and trust with the doctor-patient relationship increase willingness to accept medical advice and adherence to long-term preventative regimens such as AET. ${ }^{38-41}$ Studies show that the majority of patients still prefer to interact with health care professionals rather than gain information online or receive a booklet. ${ }^{34,42}$ In this study, women suggested the need for follow-up specific to AET to provide support, reassurance, and prompt discussion of any issues arising.

Our findings also suggest that possible avenues for support for women concerned about AET were poorly signposted and women were unclear about whom they should contact. Specialist BCNs are a point of contact for these women, but once discharged, women no longer perceive it as the nurse's role. Long-term follow-up is with the GP, and thus, GPs have a potentially important role to play, especially as the length of hospital follow-up decreases and the recommended duration of AET increases. While adherers in our study were generally quite positive about the GP relationship, nonadherers were more ambivalent and critical of their specific knowledge. 
This highlights the importance of ensuring that GPs are educated regarding the issues experienced by women taking AET so they can provide more accurate information and support and encourage adherence. Even following a period of nonadherence, GPs could have an important role in helping women understand that restarting may still be beneficial. ${ }^{43}$ Alternatively, novel pathways could be explored, such as a nurse-led discharge intervention, a primary care nurse cancer care review, and a community pharmacist-led intervention.

\section{Strengths and limitations}

The qualitative methods of inquiry used in this study provided richer and more detailed information about adherence behaviors and opportunities and interventions to improve adherence to AET. The inclusion of a sample of nonadherers as well as adherers is a particular strength. Although our participants varied in terms of socio-demographic characteristics and presented a range of views, we were not able to recruit younger nonadherent women and the adherers therefore had a greater age range. Furthermore, we were not able to recruit from the black and minority ethnic groups. It should also be noted that a large proportion of women in our sample were on tamoxifen and that the experiences of women on AIs may be different and under-represented in our sample. For example, joint pain is a recognized side effect of AIs, which was not reported by women in our study. Furthermore, as with all qualitative studies, the small sample size and the purposive sampling strategy mean that the results may not be generalizable to a wider population. However, qualitative study designs provide depth and insight, identify nuances that may not have been identified through other methods, help inform the acceptability, and provide patient-centered approaches to the developing interventions.

\section{Conclusion}

Improving adherence to AET will reduce recurrence of and mortality from breast cancer. However, medication-taking behavior is complex and involves patient, health professional, and process components. Medication adherence is not exclusively the responsibility of the patient. This qualitative study has provided an in-depth description of factors, which can influence adherence to AET, and points to interventions that could assist in improving adherence. These include the provision of timely information on the efficacy of AET, preparing expectations around side effects, and providing information and support on how to manage burdensome side effects. Good communication and trust between the health professionals and the patient are important. Doctors should follow a patient-centered approach to care that promotes active patient involvement in the decision-making process around AET. Training and education around AET for GPs should be considered, and novel care pathways to help manage the medication, such as primary care nurse cancer care review and community pharmacist follow-up, should be explored.

\section{Acknowledgments}

We are very grateful to all the women who participated in this interview study. We are also grateful to the Independent Cancer Patients' Voice and Breast Cancer Care for helping us in recruitment to the study. This study was funded by the Faculty of Health and Life Sciences, Oxford Brookes University.

\section{Author contributions}

$\mathrm{JB}, \mathrm{MB}$, and EKW made substantial contributions to the acquisition of data, analysis, and interpretation of data. All authors made substantial contributions to the conception and design of the study and have been involved in drafting the article or revising it critically for important intellectual content and given final approval of the version to be published.

\section{Disclosure}

The authors report no conflicts of interest in this work.

\section{References}

1. World Health Organization (WHO). Adherence to long term therapies: evidence for action [online]; 2014. Available from: http://apps.who.int/iris/ bitstream/10665/42682/1/9241545992.pdf. Accessed March 5, 2016.

2. Cancer Research UK. Cancer Statistics Reports for the UK; 2016. Available from: http://www.cancerresearchuk.org/about-cancer/whatis-cancer/understanding-cancer-statistics-incidence-survival-mortality. Accessed August 14, 2016.

3. Wilkington L. Patterns of Breast Cancer Recurrence and Associated Health Care Costs of 1000 Patients Treated in Leeds: A Longitudinal Study. UK: National Cancer Intelligence Network; 2012.

4. Dowsett M, Cuzick J, Ingle J, et al. Meta-analysis of breast cancer outcomes in adjuvant trials of aromatase inhibitors versus tamoxifen. J Clin Oncol. 2010;28(3):509-518.

5. Goss PJ, Ingle N, Pritchard KI, et al. A randomized trial (MA.17R) of extending adjuvant letrozole for 5 years after completing an initial 5 years of aromatase inhibitor therapy alone or preceded by tamoxifen in postmenopausal women with early-stage breast cancer. J Clin Oncol. 2016;34(suppl):abstrLBA1.

6. Davies C, Pan H, Godwin J, et al; Adjuvant Tamoxifen: Longer Against Shorter (ATLAS) Collaborative Group. Long-term effects of continuing adjuvant tamoxifen to 10 years versus stopping at 5 years after diagnosis of oestrogen receptor-positive breast cancer: ATLAS, a randomised trial. Lancet. 2013;381(9869):805-816.

7. Goss PE, Ingle JN, Martino S, et al. Randomized trial of letrozole following tamoxifen as extended adjuvant therapy in receptor-positive breast cancer: updated findings from NCIC CTG MA.17. J Natl Cancer Inst. 2005;97(17):1262-1271. 
8. Howell A, Cuzick J, Baum M, et al; ATAC Trialists' Group. Results of the ATAC (Arimidex, Tamoxifen, Alone or in Combination) trial after completion of 5 years' adjuvant treatment for breast cancer. Lancet. 2005;365(9453):60-62.

9. Gray R. 10 years of tamoxifen better than 5 in reducing breast cancer recurrence and death. J Clin Oncol. 2014;32(21):2255-2269.

10. Murphy CC, Bartholomew LK, Carpentier MY, Bluethmann SM, Vernon SW. Adherence to adjuvant hormonal therapy among breast cancer survivors in clinical practice: a systematic review. Breast Cancer Res Treat. 2012;134(2):459-478.

11. Makubate B, Donnan PT, Dewar JA, Thompson AM, McCowan C. Cohort study of adherence to adjuvant endocrine therapy, breast cancer recurrence and mortality. Br J Cancer. 2013;108(7):1515-1524.

12. McCowan C, Shearer J, Donnan PT, et al. Cohort study examining tamoxifen adherence and its relationship to mortality in women with breast cancer. Br J Cancer. 2008;99(11):1763-1768.

13. McCowan C, Wang S, Thompson AM, Makubate B, Petrie DJ. The value of high adherence to tamoxifen in women with breast cancer: a community-based cohort study. Br J Cancer. 2013;109(5):1172-1180.

14. Brett J, Fenlon D, Boulton M, et al. Factors associated with intentional and unintentional non-adherence to adjuvant endocrine therapy following breast cancer. Eur J Cancer Care (Engl). Epub 2016 Nov 30:doi: 10.1111/ecc.12601.

15. Cahir C, Guinan E, Dombrowski SU, Sharp L, Bennett K. Identifying the determinants of adjuvant hormonal therapy medication taking behaviour in women with stages IIII breast cancer: a systematic review and meta-analysis. Patient Educ Couns. 2015;98(12): 1524-1539.

16. Moon Z, Moss-Morris R, Hunter MS, Carlisle S, Hughes LD. Barriers and facilitators of adjuvant endocrine therapy adherence and persistence in women with breast cancer: a systematic review. Patient Prefer Adherence. 2017;11:305-322.

17. Harrow A, Dryden R, McCowan C, et al. A hard pill to swallow: a qualitative study of women's experiences of adjuvant endocrine therapy for breast cancer. BMJ Open. 2014;4(6):e005285.

18. Cahir C, Dombrowski SU, Kelly CM, Kennedy MJ, Bennett K, Sharp L. Women's experiences of hormonal therapy for breast cancer: exploring influences on medication-taking behaviour. Support Care Cancer. 2015;23(11):3115-3130.

19. McGinnis B, Olson KL, Magid D, et al. Factors related to adherence to statin therapy. Ann Pharmacother. 2007;41(11):1805-1811.

20. Ritchie J, Spencer L. Qualitative data analysis for applied policy research. In: Bryman A, Burgess R, editors. Analyzing Qualitative Data. London: Routledge; 1993:173-194.

21. Horne R, Chapman S, Parham R, Freemantle N, Forbes A, Cooper V. Understanding patients' adherence-related beliefs about medicines prescribed for long term condition: a meta-analytic review of the necessity-concerns framework. PLoS One. 2013;8(12):e80633.

22. Horne R, Hankins M, Weinman J. The beliefs about Medicines Questionnaire: the development and evaluation of a new method for assessing the cognitive representation of medication. Psychol Health. 1999; $14: 1-24$.

23. Carter SR, Moles R, White L, Chen TF. Medication information seeking behavior of patients who use multiple medicines: how does it affect adherence. Patient Educ Couns. 2013;92(1):74-80.

24. Wouters H, Stiggelbout AM, Bouvy ML. Endocrine therapy for breast cancer: assessing an array of women's treatment experiences and perceptions, their perceived self-efficacy and non-adherence. Clin Breast Cancer. 2014;14(6):467-467.e2.

25. Grunfeld EA, Hunter MS, Sikka P, Mittal S. Adherence beliefs among breast cancer patients taking tamoxifen. Patient Educ Couns. 2005; 59(1):97-102.

26. Llewellyn CD, McGurk M, Weinman J. Head and neck cancer: to what extent can psychological factors explain differences between health-related quality of life and individual quality of life? $\mathrm{Br} \mathrm{J}$ Oral Maxillofac Surg. 2005;44(5):351-357.
27. Llewellyn CD, McGurk M, Weinman J. The Relationship Between the Patient Generated Index (PGI) and measures of HR-QoL following diagnosis with head and neck cancer: are illness and treatment perceptions determinants of judgment-based outcomes? Br J Health Psychol. 2007;12(3):421-437.

28. Manigat P, Gorden BR, Breslow JL. How do we improve patient compliance and adherence to long-term statin therapy? Curr Atheroscler Rep. 2013;15(1):291.

29. National Institute for Health and Care Excellence (NICE) Guidance [webpage on the Internet]. Patient Experience in Adult NHS Services: Improving the Experience of Care for People Using Adult NHS Services. NICE; 2012. Available from: https://www.nice.org.uk/guidance/ cg138. Accessed March 16, 2016.

30. National Institute for Health and Care Excellence (NICE) Guidance [CG76] [webpage on the Internet]. Medicines Adherence: Involving Patients in Decisions about Prescribed Medicines and Supporting Adherence; 2009. Available from: https:/www.nice.org.uk/guidance/ cg76. Accessed March 16, 2016.

31. Corner J, Bailey CB. Cancer Nursing: Care in Context. 2nd ed. London: Blackwells Publishing; 2008.

32. Finnegan-John J, Thomas VJ. The psychosocial experience of patients with end-stage renal disease and its impact on quality of life: findings from a needs assessment to shape a service ISRN. Nephrology. 2012; 2013:308986.

33. DiMatteo RM, Haskard-Zolnierek KB, Martin LR. Improving patient adherence: a three-factor model to guide practice. Health Psychol. 2012; Rev 6:74-91.

34. Naik G, Ahmed H, Edwards A. Communicating risk to patients and the public. Br J Gen Pract. 2012;62(597):213-216.

35. Davidson B, Vogel V, Wickerham L. Oncologist-patient discussion of adjuvant hormonal therapy in breast cancer results of a linguistic study focusing on adherence and persistence to therapy. J Support Oncol. 2007;5(3):139-143.

36. Brown MT, Bussell JK. Medication adherence: WHO cares? Rev Mayo Clin Proc. 2011;86(4):304-314.

37. Costa E, Giardini A, Savin M, et al. Interventional tools to improve medication adherence: review of literature. Patient Prefer Adherence. 2015;9:1303-1314.

38. Freeman $\mathrm{G}$, Hughes $\mathrm{J}$ [homepage on the Internet]. Continuity of Care and the Patient Experience. The Kings Fund; 2010. Available from: https://www.kingsfund.org.uk/sites/default/files/field/field_document/ continuity-care-patient-experience-gp-inquiry-research-paper-mar11. pdf. Accessed March 5, 2016.

39. Brookhart MA, Patrick AR, Schneeweiss S, et al. Physician follow-up and provider continuity are associated with long-term medication adherence: a study of the dynamics of statin use. Arch Intern Med. 2007; 167(8):847-852.

40. Von Bültzingslöwen I, Eliasson G, Sarvimäki A, Mattsson B, Hjortdahl P. Patients' views on interpersonal continuity in primary care: a sense of security based on four core foundations. Fam Prac. 2006;23: 210-219.

41. Osterberg L, Blaschke T. Adherence to medication. NEngl J Med. 2005; 353(5):487-497.

42. Fletcher C, Flight I, Chapman J, Fennell K, Wilson C. The information needs of adult cancer survivors across the cancer continuum: a scoping review. Patient Educ Couns. 2017;100(3):383-410.

43. Zdenkowski N, Forbes JF, Boyle FM, et al; Australia and New Zealand Breast Cancer Trials Group. Observation versus late reintroduction of letrozole as adjuvant endocrine therapy for hormone receptor-positive breast cancer (ANZ0501 LATER): an open-label randomised, controlled trial. Ann Oncol. 2016;27(5):806-812. 


\section{Publish your work in this journal}

Patient Preference and Adherence is an international, peer-reviewed, open access journal that focuses on the growing importance of patient preference and adherence throughout the therapeutic continuum. Patient satisfaction, acceptability, quality of life, compliance, persistence and their role in developing new therapeutic modalities and compounds to optimize

clinical outcomes for existing disease states are major areas of interest for the journal. This journal has been accepted for indexing on PubMed Central. The manuscript management system is completely online and includes a very quick and fair peer-review system, which is all easy to use. Visit http://www. dovepress.com/testimonials.php to read real quotes from published authors.

Submit your manuscript here: http://www.dovepress.com/patient-preference-and-adherence-journal 